\title{
Factores asociados a exacerbaciones de EPOC en hospitales de primer nivel, Colombia
}

\section{PLANTEAMIENTO DEL PROBLEMA}

Las enfermedades no transmisibles son la causa de muerte más importante en el mundo, representan en su conjunto alrededor del $70 \%$ del número total de muertes anuales. El $80 \%$ de los pacientes con EPOC presentan agudizaciones periódicas de sus síntomas que suelen aumentar progresivamente en frecuencia e intensidad, constituyendo uno de los factores determinante de la mala calidad de vida de estos enfer mos y una causa frecuente de muerte.

\begin{tabular}{|l|} 
OBJETIVO \\
\begin{tabular}{|l|} 
Se buscó determinar los \\
factores asociados a las \\
exacerbaciones de EPOC en \\
los servicios de urgencias de \\
hospitales de primer nivel \\
de 8 municipios del área \\
cafetera de Colombia \\
\hline
\end{tabular}
\end{tabular}

\section{RESULTADOS}

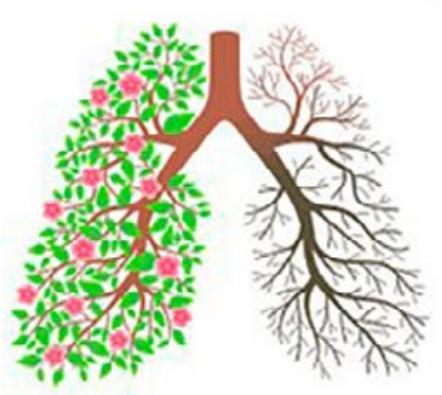

\section{METODOLOGÍA}

Se realizó un estudio descriptivo, observacional, tomando como población los pacientes que acudan al servicio de urgencias de 8 hospitales de primer nivel diagnosticados con EPOC y que motivan la consulta al servicio de urgencias, entre los meses de febrero y junio del 2018. El instrumento de recolección de datos permitió registrar variables demográficas descriptivas como edad, sexo, procedencia, etnia, motivo de consulta y entidad de salud. También se incluyeron preguntas buscando identificar los factores asociados a su exacerbación planteadas por las guías internacionales. Los datos fueron recolectados por medio de un instrumento aplicado a los pacientes previo consentimiento informado. Los datos fueron compilados en una matriz de Excel 2010 y analizados con un software estadístico..

Se observó un promedio de edad de 70 años (DE 16.5), se encuentra mayor preponderancia en el género masculino con un $\mathbf{5 8 . 5 4 \%}$ con predominio de la patología en la zona rural. La mayoría de pacientes presentan más de 2 exacerbaciones por año con un $51.22 \%$, aumentando la susceptibilidad para adquirir infecciones respiratorias con $41.46 \%$, además incumplimiento con su oxigenoterapia y la exposición a tóxicos ambientales.

\begin{tabular}{|c|c|}
\hline \multicolumn{2}{|l|}{ Edad } \\
\hline promedio & 70,93 \\
\hline DE & 11,50 \\
\hline Max & 91 \\
\hline Min & 39 \\
\hline Sex & $\%$ \\
\hline Femenino & 41,46 \\
\hline Masculino & 58,54 \\
\hline Origen & $\%$ \\
\hline Urbano & 41,46 \\
\hline Rural & 58,54 \\
\hline Escolaridad & $\%$ \\
\hline Primaria & 87,80 \\
\hline Secundaria & 7,32 \\
\hline Técnico & 4,88 \\
\hline Universitario & 0,00 \\
\hline
\end{tabular}

Tabla 1. Datos demográficos de pacientes con exacerbaciones de EPOC en municipios de Risaralda Colombia, 2018

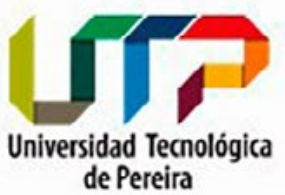

\begin{tabular}{|r|l|l|}
\hline Factor Infección respiratoria & $\%$ & P valor \\
\hline No adherencia al tratamiento & 29,27 & 0.1 \\
\hline $\begin{array}{r}\text { Exposición a tóxicos ambientales } \\
\text { Enfermedades coexistentes }\end{array}$ & $\begin{array}{l}34,15 \\
17,07\end{array}$ & 0.2 \\
\hline Tres o más exacerbaciones en el & 51,22 & 0.08 \\
ałlo & & \\
\hline Tabaquismo activo & 12,20 & 0.85 \\
\hline No adherencia al tratamiento 0 al & 36,59 & 0.2 \\
\hline oxigeno & & \\
\hline
\end{tabular}

Tabla 2. Factores asociados con exacerbaciones de EPOC en municipios de Risaralda Colombia, 2018

\section{CONCLUSIONES}

La EPOC continúa siendo causa importante de consulta a los servicios de urgencias. Los factores relacionados con su exacerbación están asociados a hábitos que tienen que ver con las conductas de los pacientes frente a su enfermedad y con el irregular cumplimiento de las indicaciones médicas, lo cual pone de manifiesto la necesidad de aumentar los esfuerzos en educación de esta población y sus cuidadores. 